\title{
Estimation of Tilt in Characters and Correction for better Readability by OCR Systems
}

\author{
C. S. Vijayashree \\ P.E.T Research Centre, \\ PES College of Engg. \\ Mandya, India-571401
}

\author{
Vishwanath C. Kagawade \\ Basaveswara College of Engg. \\ Bagalkot \\ India
}

\author{
T. Vasudev \\ Maharaja Research Foundation \\ MIT Campus, Belawadi, \\ S R Patna, India-571438
}

\begin{abstract}
The existing Optical Character Readers (OCRs) are capable of reading linear form text and have limitations to read artistic and non-linear form text. The tilt in characters contributes a major share in affecting the efficiency of the recognition algorithms. This paper presents a technique to estimate and correct the vertical tilt in printed characters of English in order to make an OCR to read the text more efficiently. The input characters are assumed to be segmented from the document image and free from noise. Initially, the direction of tilt of the characters is detected using a heuristically constructed knowledgebase. Next, the inclination of the character to its base is estimated using line drawing algorithm. Finally, the estimated tilt is corrected through rotation in counter direction of the tilt. The method has been tested with sufficient samples and readability analysis is performed with an OCR. Experimental results show an average improvement in readability by OCR from $20 \%$ before tilt correction to $82 \%$ after the tilt correction.
\end{abstract}

\section{Keywords}

Linear text, Artistic text, Tilt in characters, Tilt correction, OCR.

\section{INTRODUCTION}

A significant area in the field of Digital Image Processing is Document Image Analysis(DIA). DIA is very important in applications like document identification/recognition, language identification, automatic reading from document etc. Many researchers are working on different problems on document images starting from image acquisition to image understanding [1,2]. Processing activities in DIA can be divided into Pre-processing, Segmentation, Script Identification, Page Layout Analysis (PLA) and Classification, Character Recognition etc [3], and these have lead into many vibrant research problems [2]. The results of the research on the above problems are gradually converging towards generic solutions to major issues in DIA.

In spite of considerable research work in the area of DIA, a major issue which is not sufficiently addressed is the detection and correction of skew or tilt in characters. Tilt is the angular slant to the baseline introduced in the character. Tilted characters are mainly noticed in many artistic texts. Fig. 1 shows few samples of text with tilted characters. The characters extracted from such artistic text exhibit inherent tilt considerably. Fig. 2 show few examples of tilted characters segmented from artistic text. Such tilted characters hinder the investigation of generic methods of recognition and the efficiency of recognition drops relatively. Hence tilt in characters contributes a major share in affecting the efficiency of the recognition algorithms.
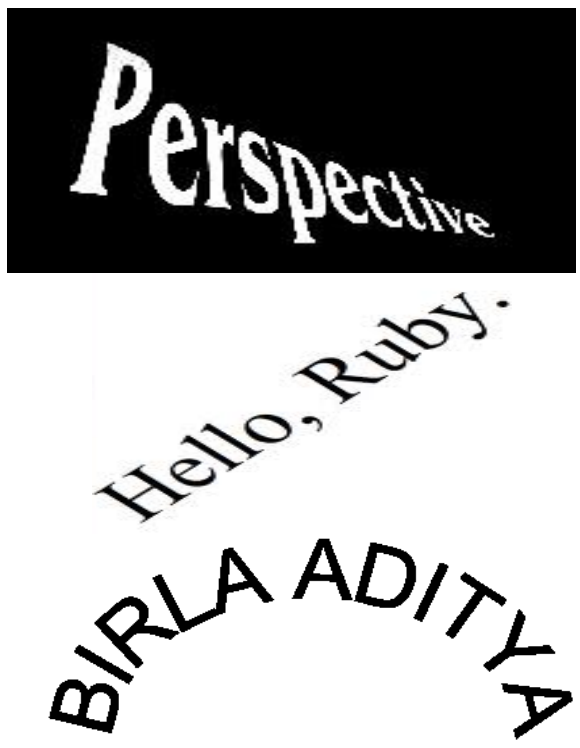

Fig 1: Samples of Artistic Text with Tilt in Characters
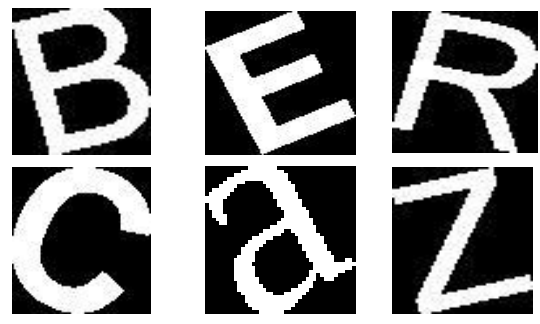

Fig 2: Samples of Tilted Characters

Literature survey reveals that most of the character recognition algorithms assume that the input is tilt corrected. When tilted characters are subjected to recognition through any existing algorithms, the rate of recognition obviously becomes low. The rate of character recognition is inversely proportional to the degree of tilt in characters i.e. higher the degree of tilt, lower is the recognition rate [4-6].

Considerable amount of research is reported in literature on the skew detection [7-13] and correction of document images. The document skew detection and correction algorithms cannot be extended to detect and correct tilt in characters. The characteristics considered for detection of skew at document level is different from the characteristics considered for skew detection at character level. Generally, global characteristics of the document like finding line orientations using Hough transformations [9], slope between nearest-neighbor chain(NNC) obtained in the documents [13], horizontal 
projection profile of the document and its Wigner-Ville distribution for documents [10] etc., are considered in case of document level skew detection. Local features of the characters are to be considered for detecting the tilt in characters. Not many attempts have been made towards detecting tilt at character level. This motivated us to make an attempt to detect and correct the character tilt before subjecting the tilted text characters for reading through OCRs.

The characters extracted from any artistic form text possess an implicit tilt [14]. Due to this OCRs fail considerably to read such tilted characters. In this research work, we propose a methodology to estimate and correct the vertical tilt of printed characters of English subjected for recognition. The input to the method is the segmented characters obtained from an artistic text through connected component labeling $[15,16]$. The proposed method initially performs a macro level decision to find the direction of tilt i.e. detection of tilt is towards left or right from baseline. The proposed tilt detection algorithm detects the direction of tilt in the input character with the support of a heuristic knowledgebase. Next, the degree of tilt to the baseline is estimated using line drawing algorithm. Finally the character is rotated by the estimated tilt in the counter direction of the tilt.

The block diagram shown in Fig. 3 indicates the sequence of different processing stages performed in the proposed system. Input to the procedure is a character which is segmented from a document image containing artistic text.

The rest of the paper is organized as follows: The detection of the direction of tilt in characters is explained in section 2. Tilt angle estimation and correction of tilt in the input character is explained in section 3. Section 4 explains the methodology used. Experimental results are illustrated in section 5. Section 6 explains some of the limitations scenarios and conclusion is given in section 7 .

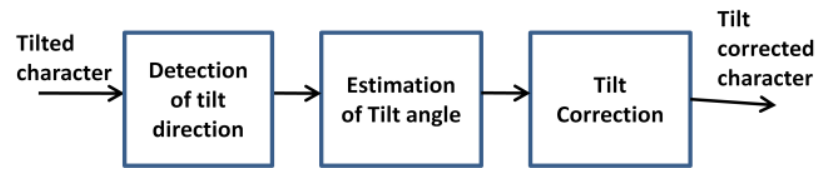

Fig 3: Sequence of Stages in the Proposed Work

\section{DETECTION OF TILT DIRECTION}

A character may be tilted towards left or right direction from baseline. It is essential to detect the direction of tilt before estimating the angle of tilt.

Tilt direction in the character is detected with the help of a heuristically constructed knowledgebase. Knowledgebase is a repository of derived information [17]. An inference engine is used for deriving such knowledge on direction of tilt. In the proposed method, the knowledgebase is constructed about the corner areas of the rectangular boundary enclosing the character. The corner areas are heuristically fixed by the triangle formed with sides equal to $(1 / 5)^{\text {th }}$ of width and $(1 / 5)^{\text {th }}$ of height respectively at each corners of the rectangle as shown in Fig. 4. The knowledgebase is developed using the heuristics on non tilted structure of the character. The knowledgebase enables us to make a macro level decision whether the character is left tilted or right tilted or not tilted from the baseline. In case of conflicts, the character is subjected for a second level classification based on pixel densities in corners.

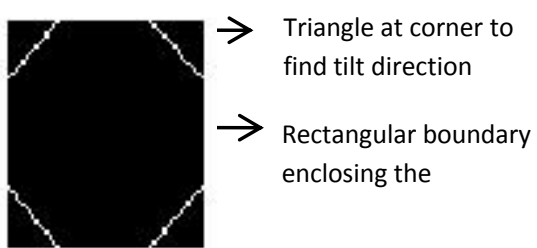

Fig 4: Corner Areas Heuristically Fixed

Few important inferences that are derived from the knowledgebase constructed through the heuristics of character structures are listed in Table 1.

Table 1. Rules for Tilt Direction Detection

\begin{tabular}{|c|c|c|c|c|c|c|}
\hline \multirow[t]{2}{*}{ SIno. } & \multicolumn{4}{|c|}{ Presence of a part of the Character } & \multirow[t]{2}{*}{ Tilt } & \multirow[t]{2}{*}{ Direction } \\
\hline & Left Top & Right Top & Left Bottom & Right Bottom & & \\
\hline 1 & $\mathrm{~N}$ & $\mathrm{Y}$ & $\mathrm{Y}$ & $\mathrm{N}$ & Yes & Right \\
\hline 2 & $\bar{Y}$ & $\mathrm{~N}$ & $\mathrm{~N}$ & $\bar{Y}$ & Yes & Left \\
\hline 3 & $\mathrm{Y}$ & $\mathrm{Y}$ & $\mathrm{N}$ & $\mathrm{Y}$ & Conflict & [a] \\
\hline 4 & $\bar{Y}$ & $\bar{Y}$ & $\mathrm{Y}$ & $\mathrm{N}$ & Conflict & [b] \\
\hline 5 & $\mathrm{Y}$ & $\mathrm{N}$ & $\mathrm{Y}$ & $\mathrm{Y}$ & Yes & Left \\
\hline 6 & $\mathrm{Y}$ & $\mathrm{N}$ & $\mathrm{N}$ & $\mathrm{N}$ & Yes & Left \\
\hline 7 & $\mathrm{~N}$ & $\mathrm{~N}$ & $\mathrm{~N}$ & $\mathrm{Y}$ & Yes & Left \\
\hline 8 & $\mathrm{~N}$ & $\mathrm{Y}$ & $\mathrm{N}$ & $\mathrm{N}$ & Yes & Right \\
\hline 9 & $\mathrm{~N}$ & $\mathrm{~N}$ & $\mathrm{Y}$ & $\mathrm{N}$ & Yes & Right \\
\hline 10 & $\mathrm{~N}$ & $\mathrm{Y}$ & $\mathrm{Y}$ & $\mathrm{Y}$ & Conflict & [c] \\
\hline 11 & $\mathrm{Y}$ & $\mathrm{Y}$ & - & - & Conflict & [d] \\
\hline 12 & $\mathrm{~N}$ & $\mathrm{~N}$ & $\mathrm{~N}$ & $\mathrm{~N}$ & Conflict & [e] \\
\hline 13 & $\mathrm{Y}$ & $\mathrm{Y}$ & $\mathrm{Y}$ & $\mathrm{Y}$ & No & - \\
\hline
\end{tabular}


In case of conflicts [a] through [d], a next level decision is carried out to detect tilt based on the density of the pixels in the corner areas of the rectangle box. The pixel densities in the four corners are computed as left top density (LTD), right top density (RTD), left bottom density (LBD) and right bottom density (RBD). A decision rule is devised as given in Table 2 to make the second level decision to detect tilt direction for conflict cases[a] through [d] of Table 1 .

The conflict case [e] arises when no part of the character is found in any of the corner areas of the rectangular boundary enclosing the character as shown in Fig. 6(a). In order to handle such conflicts, another set of decision rules are applied to detect the direction of tilt. The rectangular area defining the character is divided into 4 equal quadrants as in Fig. 6(b). The decision on direction of tilt is then based on the position of the edge of the character touching the outer boundary in the 4 quadrants. The outer edges of the quadrants formed in the rectangular boundary enclosing the character are named as illustrated in Fig. 6(b).

Table 2. Second Level Rules for Tilt Direction Detection

\begin{tabular}{|c|c|c|}
\hline $\begin{array}{c}\text { Conflict } \\
\text { Case }\end{array}$ & Conditions & $\begin{array}{c}\text { Tilt } \\
\text { Direction }\end{array}$ \\
\hline \multirow[t]{2}{*}{$\mathrm{a}$} & RTD $>$ LTD & Left \\
\hline & $(\mathrm{RBD}>\mathrm{RTD})$ and $(\mathrm{RBD}>\mathrm{LTD})$ & Left \\
\hline \multirow[t]{3}{*}{$\mathrm{b}$} & LTD $>$ RTD & Right \\
\hline & $(\mathrm{LBD}>\mathrm{RTD})$ and $(\mathrm{LBD}>\mathrm{LTD})$ & Right \\
\hline & $(\mathrm{RTD}>\mathrm{LTD})$ and $(\mathrm{RTD}>\mathrm{LBD})$ & Right \\
\hline \multirow[t]{2}{*}{$\mathrm{c}$} & RBD > LBD & Right \\
\hline & $\mathrm{RBD}<\mathrm{LBD}$ & Right \\
\hline \multirow[t]{2}{*}{$\mathrm{d}$} & RTD > LTD & Left \\
\hline & $(\mathrm{LTD}>\mathrm{RTD})$ and $(\mathrm{LBD}<\mathrm{RBD})$ & Left \\
\hline
\end{tabular}

The outer edges labelled $\mathbf{h}_{\mathbf{k}}$ and $\mathbf{v}_{\mathbf{k}}$ represent horizontal and vertical edges respectively of $\mathbf{k}^{\text {th }}$ quadrant. $\mathbf{P}_{\mathbf{k}}$ represents a point on the edge in $\mathbf{k}^{\text {th }}$ quadrant. An operator ó is defined in this method to find a point of the character touching an edge of the bounding box. The notation $\left(\mathbf{P}_{\mathbf{k}} \mathbf{0} \mathbf{v}_{\mathbf{k}}\right)$ indicates the point at which character touches the edge $\mathbf{v}_{\mathbf{k}}$. The decision rules for tilt direction detection in conflict case [e] is illustrated in Table 3.

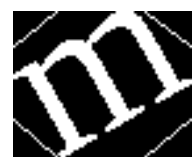

Fig 6(a): No Part of Character in the Corner Triangles

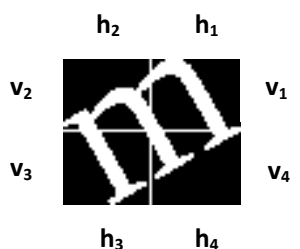

Fig 6(b): Four Quadrants Defined with Fdoes I ahelled
The knowledgebase constructed is used as a supporting system to enable a macro level detection of direction of tilt. As the knowledgebase is constructed based on the structure of English characters, experimentation is carried out on good number of tilted English characters. In general, the developed model provides optimum results for tilt angles between $5^{\circ}$ $45^{\circ}$. The method is tested for both upper case and lower case characters. When the tilt angle is outside this range, the corner area triangle methodology does not provide definite results. For the English characters with tilt between $5^{\circ}-45^{\circ}$, the success rate is around 93\%. Once the direction of tilt is detected the character is subjected for estimation of tilt angle. The procedure for estimating the angle of tilt in the character is explained in the subsequent section.

Table 3. Decision Rules for Tilt Direction. Detection in Conflict Case [e]

\begin{tabular}{|c|c|c|}
\hline Case & Conditions & $\begin{array}{c}\text { Tilt } \\
\text { Direction }\end{array}$ \\
\hline $\mathrm{a}$ & $\begin{array}{c}\left(\mathrm{p}_{2} \mathrm{o} \mathrm{v}_{2}\right) \text { and }\left(\mathrm{p}_{4} \mathrm{o}_{4}\right) \text { and }\left(\mathrm{p}_{1} \mathrm{ó} \mathrm{h}_{1}\right) \text { and } \\
\left(\mathrm{p}_{3} \mathrm{o}_{3}\right)\end{array}$ & Left \\
\hline $\mathrm{b}$ & $\begin{array}{c}\left(\mathrm{p}_{3} \mathrm{o} \mathrm{v}_{3}\right) \text { and }\left(\mathrm{p}_{1} \mathrm{ov}_{1}\right) \text { and }\left(\mathrm{p}_{2} \mathrm{ó} \mathrm{h}_{2}\right) \text { and } \\
\left(\mathrm{p}_{4} \mathrm{o} \mathrm{h}_{4}\right)\end{array}$ & Right \\
\hline $\mathrm{c}$ & $\begin{array}{c}\left(\mathrm{p}_{2} \mathrm{ó}_{2}\right) \text { and }\left(\mathrm{p}_{4} \mathrm{ov}_{4}\right) \text { and }\left(\mathrm{p}_{1} \mathrm{ó} \mathrm{h}_{1}\right) \text { and } \\
\left(\mathrm{p}_{4} \mathrm{ó}_{4}\right)\end{array}$ & Left \\
\hline $\mathrm{d}$ & $\begin{array}{c}\left(\mathrm{p}_{2} \mathrm{o} \mathrm{h}_{2}\right) \text { and }\left(\mathrm{p}_{1} \mathrm{o} \mathrm{v}_{1}\right) \text { and }\left(\mathrm{p}_{3} \mathrm{o} \mathrm{v}_{3}\right) \text { and } \\
\left(\mathrm{p}_{3} \mathrm{o}_{3}\right)\end{array}$ & Right \\
\hline $\mathrm{e}$ & $\begin{array}{c}\left(\mathrm{p}_{2} \mathrm{ó}_{2}\right) \text { and }\left(\mathrm{p}_{4} \mathrm{ó}_{4}\right) \text { and } \\
\operatorname{not}\left(\mathrm{p}_{1} \mathrm{o}_{1}\right) \text { and }\left(\left(\mathrm{p}_{4} \mathrm{ov}_{4}\right) \operatorname{or}\left(\mathrm{p}_{1} \mathrm{ov}_{1}\right)\right)\end{array}$ & Left \\
\hline$f$ & $\begin{array}{c}\left(\mathrm{p}_{3} \mathrm{ó}_{3}\right) \text { and }\left(\mathrm{p}_{1} \mathrm{óh}_{1}\right) \text { and } \\
\operatorname{not}\left(\mathrm{p}_{2} \mathrm{o}_{2}\right) \operatorname{and}\left(\left(\mathrm{p}_{4} \mathrm{ó}_{4}\right) \operatorname{or}\left(\mathrm{p}_{3} \mathrm{óh}_{3}\right)\right)\end{array}$ & Right \\
\hline g & $\begin{array}{c}\left(\mathrm{p}_{2} \mathrm{ó}_{2}\right) \text { and }\left(\mathrm{p}_{4} \mathrm{óh}_{4}\right) \text { and }\left(\left(\mathrm{p}_{2} \mathrm{óh}_{2}\right) \text { or }\right. \\
\left.\left(\mathrm{p}_{1} \mathrm{o}_{1}\right)\right)\end{array}$ & Left \\
\hline $\mathrm{h}$ & $\begin{array}{c}\left(\mathrm{p}_{1} \mathrm{ó} \mathrm{h}_{1}\right) \text { and }\left(\mathrm{p}_{3} \mathrm{ó}_{3}\right) \text { and }\left(\left(\mathrm{p}_{1} \mathrm{ó} \mathrm{v}_{1}\right) \text { or }\right. \\
\left.\left(\mathrm{p}_{4} \mathrm{ó}_{4}\right)\right)\end{array}$ & Right \\
\hline
\end{tabular}

Fig 5 show few sample characters used for detection of tilt directions based on heuristic decision rules specified in this section.

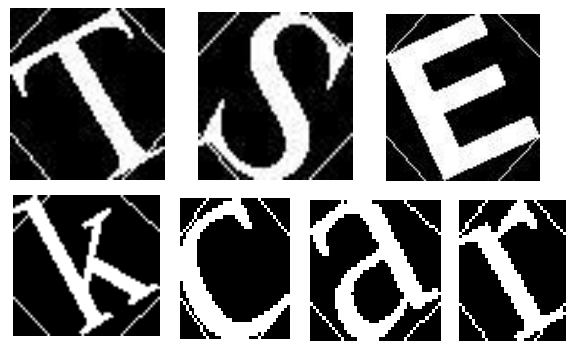

Fig 5: Samples used in Tilt Direction Detection

\section{TILT ANGLE ESTIMATION AND CORRECTION}

Once the direction of tilt is obtained, the angle of tilt in that direction is to be estimated. The estimation is done through digital differential analyser (DDA) line drawing algorithm [18]. The DDA line drawing algorithm draws a line between any two specified points. A series of lines are drawn and a specific line is selected out of them. The selected line is an approximation of the tilt of the character to the baseline. Given below is the procedure for estimating the angle of tilt for a left tilted character. 
1. In the rectangle enclosing the character, a point (A) is identified. The point $\mathrm{A}$ is obtained through a search upwards starting from the mid point of the vertical boundary on the side of the tilt. A is the first point that touches the boundary line and the same is shown in Fig. 7.

Mid Point

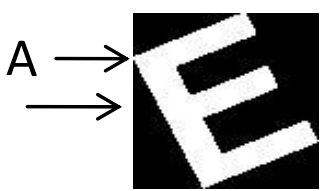

Fig 7: Identifying the Initial Point of the Line

2. A point $B$ is searched on the baseline starting from the tilt side corner point till a line is constructed that just touches the character. This procedure is illustrated in Fig. 8. The points $\mathrm{B}_{0}, \mathrm{~B}_{1}, \mathrm{~B}_{2} \ldots \mathrm{B}_{\mathrm{n}-1}, \mathrm{~B}_{\mathrm{n}}$ are the series of points searched for drawing the lines $\mathrm{AB}_{0}, \mathrm{AB}_{1}$ etc till the line drawn just touches the character. The point $B_{0}$ is the first point on the baseline starting from the side of the tilt. $B_{n}$ is the final point searched on baseline and the line $\mathrm{AB}_{\mathrm{n}}$ is the required line that touches the character. The final point $B_{n}$ on the baseline obtained is denoted as B.

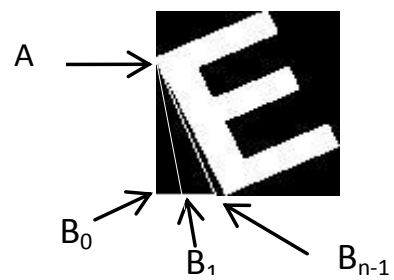

Fig. 8 Illustration of Drawing Line AB to Detect the Angle of Tilt.

3. The line $A B$ is used to identify the tilt of the character. The angle formed by line $\mathrm{AB}$ to the baseline gives the angle of tilt $\theta$ of the character. Fig. 9 illustrates the line $\mathrm{AB}$ and the angle of tilt detected.

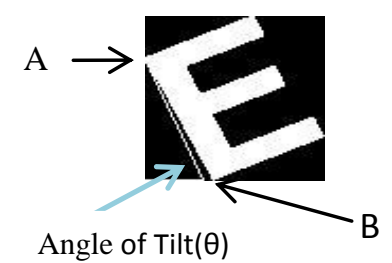

Fig 9: Line AB Used to Detect the angle of Tilt.

4. Next the character is rotated by 90 minus $\theta$ in the counter direction of tilt. Fig. 10 illustrates the tilt corrected character. Fig. 11 shows some samples of tilt corrected characters.

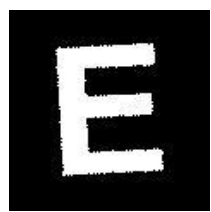

Fig 10: Tilt Corrected Character

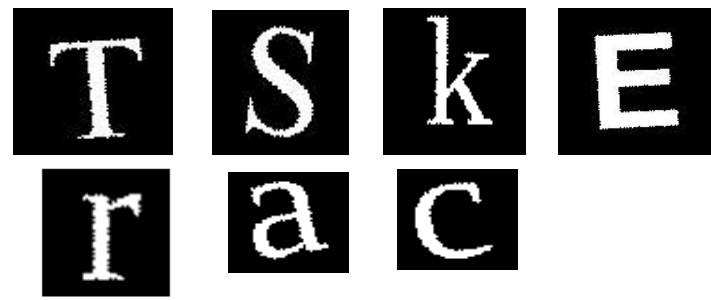

Fig 11: Characters after Tilt Angle Correction of Samples Shown in Fig. 5.

\section{METHODOLOGY}

The complete methodology used in tilt detection and correction is explained below in the form of an algorithm. The same is illustrated in Fig. 12.

1. Input character segmented from an artistic text

2. Identify the tilt direction using the knowledgebase and the rules for detecting the tilt as given in section 2

3. If the character is not tilted, exit

4 If the character is left tilted

a. Search the points A and B through the procedure explained in Section 3

b. Draw the logical line $\mathrm{L}_{1}$ from $\mathrm{A}$ to $\mathrm{B}$

c. Find the angle $\theta$ between $L_{1}$ and baseline. This is the estimated angle of tilt in the character

d. Rotate the character towards right by $90-\theta$ degrees

e. Exit

5. If the character is right tilted

a. Search the points A and B through the procedure explained in Section 3

b. Draw the logical line $\mathrm{L}_{1}$ from $\mathrm{A}$ to $\mathrm{B}$

c. Find the angle $\theta$ between $L_{1}$ and baseline. This is the estimated angle of tilt in the character

d. Rotate the character towards left by $90-\theta$ degrees

e. Exit
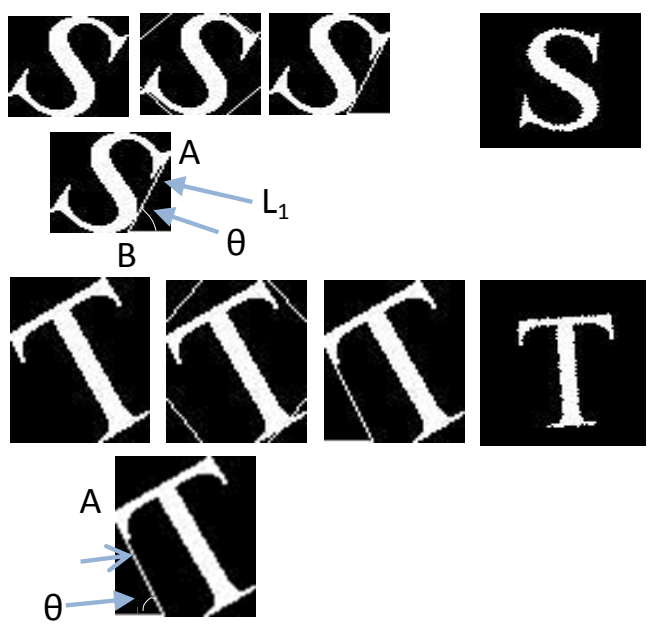

B

Fig 12: Steps in Tilt Detection and Correction 


\section{EXPERIMENTAL RESULTS}

The proposed method has been implemented in the MATLAB R2009a. Characters with different tilt are considered for testing. Optimum results have been obtained for characters within $45^{\circ}$ left or right tilt. The impact of implementation of tilt correction on characters is to increase the readability of OCR. Analysis of readability by an OCR before transformation, and after tilt correction is performed with respect to English text using the OCR "Readiris Pro 9" (http://www.irislink.com). Some of the samples tried and the results obtained are illustrated in the below Table 4.

As illustrated in Table 4, the readability of OCR is improved considerably after tilt correction of the characters implying existing OCRs are not suitable to read tilted characters. The figures of the results of tilt direction detection and estimation for tilt angle are provided in Table 5 and Table 6.

Table 4: OCR Readability Results Before and After Tilt Correction of Character.

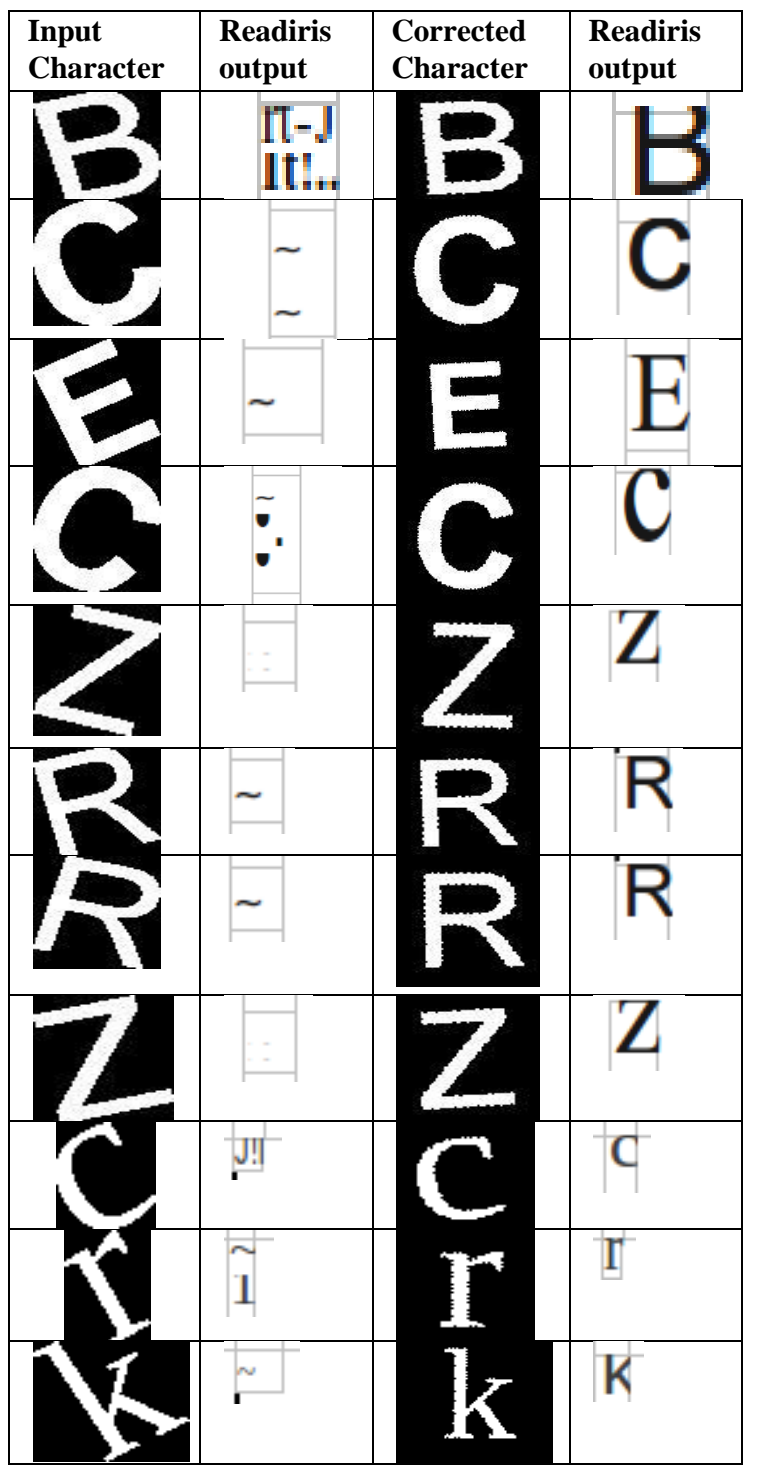

Table 5 provides the results for detection of the direction of tilt. An overall $82.31 \%$ of correct tilt direction is detected with $13.97 \%$ of incorrect detection and $3.72 \%$ of failures through the proposed method. Incorrect tilt direction detection is noticed when the tilt direction cannot be detected using the proposed algorithm. This happens in the samples when the tilt is outside the range $5^{\circ}-45^{\circ}$. Failure to detect tilt direction is also noticed when the character font styles do not fit into the decision rules formulated.

Table 6 provides the results for the estimation of the angle of tilt for the input characters that are correctly identified the direction of tilt. The proposed method to estimate the angle of tilt based on detection of tilt direction shows an overall correct tilt angle estimation of $82.25 \%$ with $8.96 \%$ over estimation and $8.79 \%$ under estimation. Correct estimation is noted when the character is aligned to $0^{\circ}$ on rotation by $90^{\circ}$ $\theta^{\circ}$ in the counter direction of tilt. Under estimation of angle of tilt is noted when counter rotation by $90^{\circ}-\theta^{\circ}$ still exhibits some residual tilt in the character. Over estimation of angle of tilt is noted when counter rotation by $90^{\circ}-\theta^{\circ}$ exhibits tilt in the direction opposite to the original direction of tilt.

Table 5: Results Obtained during Tilt Direction Detection

\begin{tabular}{|c|c|c|c|c|}
\cline { 2 - 5 } \multicolumn{1}{c|}{} & $\begin{array}{c}\text { No. } \\
\text { of } \\
\text { Samples }\end{array}$ & $\begin{array}{c}\text { No. of } \\
\text { correct } \\
\text { Detection }\end{array}$ & $\begin{array}{c}\text { No. of } \\
\text { Incorrect } \\
\text { Detection }\end{array}$ & Failures \\
\hline Left Tilt & 490 & 396 & 73 & 21 \\
\hline $\begin{array}{c}\text { Right } \\
\text { Tilt }\end{array}$ & 468 & 377 & 67 & 24 \\
\hline $\begin{array}{c}\text { Without } \\
\text { Tilt }\end{array}$ & 252 & 223 & 29 & 0 \\
\hline Total & 1210 & $\begin{array}{c}996 \\
(82.31 \%)\end{array}$ & $\begin{array}{c}169 \\
(13.97 \%)\end{array}$ & $\begin{array}{c}45 \\
(3.72 \%)\end{array}$ \\
\hline
\end{tabular}

Table 6. Results Obtained During Tilt Angle Estimation

\begin{tabular}{|c|c|c|c|c|}
\cline { 2 - 5 } \multicolumn{1}{c|}{} & $\begin{array}{c}\text { No. of } \\
\text { samples }\end{array}$ & $\begin{array}{c}\text { No. of } \\
\text { correct } \\
\text { estimation }\end{array}$ & $\begin{array}{c}\text { No. of over } \\
\text { estimation }\end{array}$ & $\begin{array}{c}\text { No. of } \\
\text { under } \\
\text { estimation }\end{array}$ \\
\hline $\begin{array}{c}\text { Left } \\
\text { Tilt }\end{array}$ & 396 & 328 & 32 & 36 \\
\hline $\begin{array}{c}\text { Right } \\
\text { Tilt }\end{array}$ & 252 & 205 & 26 & 21 \\
\hline Total & 648 & 533 & 58 & 57 \\
$(82.25 \%)$ & $(8.96 \%)$ & $(8.79 \%)$ \\
\hline
\end{tabular}

\section{LIMITATIONS SCENARIOS}

There are few instances of tilt scenarios which show error in the current methodology proposed in the previous sections. These failures scenarios are noticed in Tilt direction detection and not in the Tilt angle calculation procedures.

The errors in tilt correction are noticed due to angle of tilt, the character considered and the font style of the character. The most optimum tilt direction detection is obtained when the tilt angle is between $5^{0}$ and $45^{\circ}$. When the angle is less than $5^{\circ}$ or greater than $45^{\circ}$, the tilt direction detection is defective. This is because the logic based on the presence of character in the corner rectangles proves ineffective. For some characters, the tilt direction detection procedure does not work due to the character's inherent style, for example $\mathbf{y}, \mathbf{A}, \mathbf{v}$. Similarly some font styles do not lend themselves to the corner triangle tilt direction detection method. The tilt angle calculation method provides inaccurate results for some characters depending on the style of the character. This can be observed for some characters like $\mathbf{T}, \mathbf{f}$ and $\mathbf{d}$ in specific font styles. In some font styles characters like $\mathbf{T}$ lend themselves to overestimation of angle of tilt and characters like $\mathbf{d}$ and $\mathbf{f}$ lend themselves to 
under estimation of the angle of tilt. Fig. 13 illustrates few instances of failures in tilt direction detection. Fig. 14 illustrates few instances of over estimation of tilt angle. Fig. 15 illustrates few instances of under estimation of tilt angle.
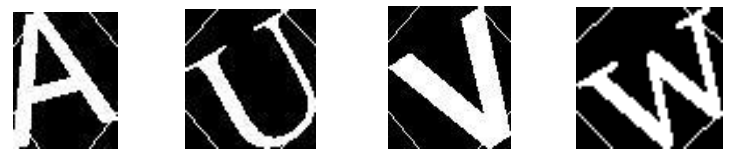

Fig 13: Samples of failures in Tilt Direction Detection

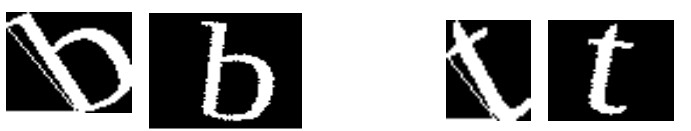

Fig 14: Characters with over estimation of tilt angle
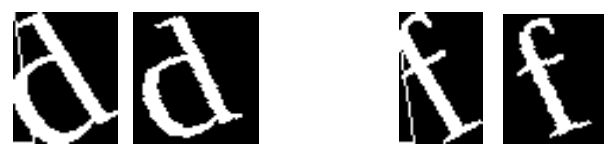

Fig 15: Characters with under estimation of tilt angle

\section{CONCLUSION}

In this paper, a method to estimate and correct the tilt in English printed text is presented which are mainly noticed in artistic text. The method is based on line drawing algorithm. The experimental results exhibit an average readability of $82 \%$ by an OCR. However, the approach has certain limitations in detecting the tilt direction and estimating the angle of tilt exactly in some cases. The failures are mainly due to fault in detection of tilt direction. However, the approach is fairly good in estimating the angle of tilt in case of correct detection of tile direction. The proposed method is not suitable for some characters like $\mathbf{A}, \mathbf{V}$ etc in some specific font styles. It is also not suitable for characters tilted at more than $45^{\circ}$. A method is under investigation to perform recursive approach to re-estimate over and under estimation of tilt angles. Further, there is much scope for research in detection of tilt direction through creating a much stronger knowledgebase. The work can be further continued to detect tilt especially for characters with large angle of tilt and handwritten characters.

\section{ACKNOWLEDGEMENT}

The authors thank the Managements and administrations of Maharaja Research Foundation, Mysore and PET Research Foundation, Mandya for their support and encouragement extended towards the research.

\section{REFERENCES}

[1] Nagabhushan P, 2001, Document Image Processing, Proc. National Pre-Conf. Workshop on Document Processing, India, pp. 114.

[2] O'Gorman, Lawrence, Rangachar, Kasturi, 1998, Executive briefing: Document image analysis, IEEE Computer Society Press.

[3] Vasudev T, Hemanthakumar G H, Nagabhushan P., 2005, Segmentation of characters in an arc-form, $7^{\text {th }}$ Int. Conf. on Cognitive Systems (ICCS 2005), India.

[4] Thomas Bayer, UlrichB, Ingrid Renz, 1997, Information Extraction from paper documents, Handbook of Character Recognition and Image Analysis, pp. 653-677

[5] Suen, Xu, Lam, 1999, Automatic recognition of handwritten data on cheques - Fact or fiction, Pattern
Recognition Letters, Vol. 20, No. 11-13, pp. 1287-1295

[6] Chatterji B N, 2001, Feature Extraction Methods for Character Recognition, Proc. National Pre-Conference Workshop on Document Processing, India, pp. 7-20

[7] Pal,U. Mitra, M.,Choudari B.B, 2001, Multi-Skew Detection of Indian Script Documents, Int. Conf. on Document Analysis and Recognition (ICDAR 2001).

[8] Gatos B et al., 1997, Skew detection and text line position determination in digitized documents, Journal of Pattern Recognition, Vol. 30, No. 9, pp. 1505-1519.

[9] Amin A, Fischer S, 2000, A Document Skew Detection Method Using the Hough Transform, Journal of Pattern Analysis and Applications, Vol 3, pp. 243-253

[10] Kavallieratou, Fakotakis, Kokkinakis, 2002, Skew Angle Estimation For Printed and Handwritten Documents Using the Wigner-Ville Distribution, Image and Vision Computing, Vol 20, pp. 813-824

[11] Liolios, Fakotakis, Kokkinakis, 2003, Generalization of the Form Identification and Skew Detection Problem, Pattern Recognition, No.35, pp. 243-264

[12] Shivakumar P, 2005, Generation of Complete Large Document Images from Split Components, Ph.D thesis under the supervision of Hemanthakumar G, University of Mysore, India

[13] Yue Lu and Chew Lim Tan, 2003, A nearest-neighbor chain based approach to skew estimation in document images, Journal of Pattern Recognition Letters, Vol 24, pp. 2315-2323.

[14] Vasudev T, Hemanthakumar G H, Nagabhushan P., 2007, "Transformation of arc-form-text linear-form-textsuitable for OCR", ScienceDirect, Pattern recognition letters 28 (2007) 2343-2351.

[15] Vishwanath C Kagawade, Vijayashree C S and Vasudev T, July 2012, Transformation of artistic form text to linear form text for OCR systems, ICAdC-2012.

[16] Vishwanath C Kagawade, Vijayashree C S and Vasudev T, Dec 2012, Transformation of artistic form text to linear form text for OCR systems using Radon Transform, ICERECT-12.

[17] Rich, Knight, 1991, Artificial Intelligence, TMH pubns.

[18] Donald Hearn, Baker M P, 2003, Computer Graphics, Pearson Education, 2nd Edition.

[19] R. E. Twogood, F. Graham Sommer, 1982, Digital Image Processing, IEEE Transactions on Nuclear Science, Vol. 29, No. 3 .

[20] P. Saragiotis and N. Papamarkos, 2008, Local Skew Correction in Documents, International Journal of Pattern Recognition and Artificial Intelligence, Vol. 22, No. 4 , 691-710, World Scientific Publishing Company.

[21] P. Nagabhushan, S.A.Anagadi et. al., Feb 2007, Geometric Model and Projection Based Algorithms for Tilt Correction and Extraction of Ascenders / Descenders for Cursive Word Recognition, IEE-ICSCN pp. 488-491.

[22] H.K.Chethan and G.Hemantha Kumar, 2010, Graphics Separation and Skew Correction of Mobile Captured Documents and Comparative analysis with Existing Methods, International Journal of Computer Science and 
Applications, Vol. 7 No. 3.

[23] Takuma Yamaguchi, Yasuaki Nakano, et.al. 2003, Digit Classification on Signboards for Telephone Number Recognition, Proceedings of the Seventh International Conference on Document Analysis and Recognition (ICDAR 2003), 0-7695-1960-1/03, IEEE.

[24] Tian Jipeng, G.Hemantha Kumar, H.K.Chethan,May 2011, Skew Correction for Chinese Character using Hough Transform, International Journal of Computer Applications (0975-8887), Volume 22- No.2.

[25] Nandini N., Srikanta Murthy K., and G. Hemantha Kumar, 2008, Estimation of Skew Angle in Binary
Document Images Using Hough Transform, World Academy of Science, Engineering and Technology 42.

[26] Rajiv Kapoor, Deepak Bagai, Kamal, 2004, A new algorithm for skew detection and correction, Science Direct, Pattern recognition letters(25), pp. 1215-1229.

[27] C.M.Velu and P.Vivekandan, June 2010, Automated letter sorting for Indian Postal Address Recognition System based on PIN codes, Journal of Internet and information system Vol. 1(1), pp. 6-15

[28] Rafael C Gonzales \& Richard E Woods, 2002, Digital Image Processing, $2^{\text {nd }}$ Ed., Pearson Education Publicatn. 